\title{
Correlations between Sexual Dysfunction, Depression, Anxiety, and Somatic Symptoms among Patients with Major Depressive Disorder
}

\author{
Chiao-Fan Lin, MD; Yeong-Yuh Juang, MD; Jung-Kwang Wen'1, MD; \\ Chia-Yih Liu, MD; Ching-I Hung, MD
}

Background: The purpose of this study was to investigate the degree of correlation between sexual dysfunction and depression, anxiety, and somatic symptoms among patients with major depressive disorder (MDD) and to identify the dimension most predictive of sexual dysfunction.

Methods: One-hundred and thirty-five outpatients with MDD were enrolled and were treated with open-label venlafaxine $75 \mathrm{mg}$ daily for one month. The Arizona Sexual Experience Scale-Chinese Version (ASEX-CV), Depression and Somatic Symptoms Scale (DSSS), Hamilton Depression Rating Scale, and Hospital Anxiety and Depression Scale (HADS) were administered at baseline and at one-month follow-up and the improvement percentage (IP) of each scale posttreatment was calculated. Multiple linear regression was used to determine the dimension most predictive of the total ASEX-CV score.

Results: Seventy subjects (20 men, 50 women) completed the one-month pharmacotherapy and the four scales. The depression subscale of the HADS was most strongly correlated with the ASEX-CV scale and was the only subscale to independently predict the total ASEX-CV score at the two points. However, the somatic subscale of the DSSS was not correlated with any ASEX-CV item. At the endpoint, depression, anxiety, and somatic symptoms were significantly improved (IP $48.5 \%$ to $26.0 \%$ ); however, very little improvement was observed in the total ASEX-CV score (IP-1.6\%).

Conclusion: The severity of sexual dysfunction among patients with MDD was most correlated with the severity of the depressive dimension, but not the severity of the somatic dimension. Further studies are indicated to explore the relationships between sexual dysfunction, depression, anxiety, and somatic symptoms.

(Chang Gung Med J 2012;35:323-31)

Key words: sexual dysfunction, depression, anxiety, somatization

$\mathrm{M}$ ental illness has a large effect on sexual function and the expression of sexuality, and many studies have illustrated that sexual dysfunction is sig- nificantly associated with depression. ${ }^{(1-3)}$ Although decreased libido is most often reported, difficulties with arousal resulting in vaginal dryness in women

From the Department of Psychiatry, Chang-Gung Memorial Hospital at Linkou, Chang Gung University College of Medicine, Taoyuan, Taiwan; ${ }^{1}$ Tsyr-Huey Mental Hospital, Kaohsiung Jen-Ai Homes, Kaohsiung Taiwan.

Received: June 21, 2011; Accepted: Dec. 28, 2011

Correspondence to: Dr. Ching-I Hung, Department of Psychiatry, Chang Gung Memorial Hospital at Linkou. 5, Fusing St., Gueishan Township, Taoyuan County 333, Taiwan (R.O.C.) Tel: 886-3-3281200 ext 2439; Fax: 886-3-3280267;

E-mail: a36250@cgmh.org.tw 
and erectile dysfunction in men and absent or delayed orgasm are also prevalent. ${ }^{(1-3)}$ These findings have been replicated cross-culturally. ${ }^{(4,5)}$ Some antidepressants have significant effects on sexual dysfunction. ${ }^{(6)}$ Although there can be side effects of treatment related to sexual dysfunction, some studies have reported improvements in depression and sexual dysfunction after antidepressant treatment. ${ }^{(6-9)}$

Several studies have reported a relationship between anxiety and sexual dysfunction. ${ }^{(10,11)}$ In addition, generalized anxiety disorder was found to be associated with a 2.6-fold greater risk of inhibited orgasm and a 2.1-fold greater risk of inhibited sexual excitement in men and women, and a 2.5 -fold greater risk of dyspareunia in women. ${ }^{(12)}$ Moreover, sexual arousal may decrease in women with anxiety of a greater severity, ${ }^{(13)}$ and women with sexual desire disorder are more worried and anxious than sexuallyfunctional women. ${ }^{(14)}$

Depression, anxiety, and somatic symptoms are correlated and interacted. Patients with major depressive disorder (MDD) often have multiple comorbid somatic symptoms, ${ }^{(15-17)}$ and sexual dysfunction has been considered a physical (or somatic) symptom of MDD. Moreover, sexual dysfunction is also common in some painful physical diseases. ${ }^{(18-20)}$ Therefore, it has been questioned whether sexual dysfunction is the same as or correlated with other somatic symptoms among patients with MDD, such as painful physical symptoms, chest tightness, muscle tension, and other symptoms. Previous studies related to sexual dysfunction and mood disorders have focused on the dimensions of depression and anxiety, ${ }^{(1)}$ but rarely having studies discussed the relationship between sexual dysfunction and other somatic symptoms among patients with MDD. ${ }^{(21)}$ To the best of our knowledge, no study has compared the degree of correlation of sexual dysfunction with depression, anxiety, and somatic symptoms among patients with MDD. Therefore, the purpose of this study was to investigate the degree of correlation of sexual dysfunction with the three dimensions (depression, anxiety, and somatic symptoms) among patients with MDD and to identify the dimension most predictive of sexual dysfunction. Based on the findings of previous studies, ${ }^{(1-3,10-12)}$ we hypothesized that 1$)$ the depression and anxiety dimensions are both correlated with sexual dysfunction, and 2) the depressive dimension might be most correlated with sexual dys- function among the three dimensions.

\section{METHODS}

\section{Subjects}

Patients were recruited into this study between January 2004 and January 2005 from the psychiatric outpatient clinic of Chang Gung Memorial Hospital, a medical center in northern Taiwan. This study was approved by the Institutional Review Board of the same hospital. The inclusion criteria were psychiatric outpatients 18-65 years old who had not taken antidepressants or other psychotropic drugs within the previous 2 weeks and who met the DSM-IV text revision (TR) criteria for MDD in a major depressive episode, ${ }^{(22)}$ which was diagnosed by a board-certified psychiatrist using the Structured Clinical Interview for DSM-IV TR Axis I Disorders. ${ }^{(23)}$ To prevent sexual dysfunction from being confounded by other medical conditions, substance abuse, or psychotic symptoms, the following exclusion criteria were established: 1) a history of substance dependence or abuse without full remission in the previous month; 2) psychotic symptoms, catatonic features, or severe psychomotor retardation resulting in obvious difficulty in being interviewed; and 3) chronic medical diseases such as hypertension, diabetes mellitus, and other medical conditions, except for headache. Informed consent was obtained from all participants before enrollment.

\section{Instruments}

The Arizona Sexual Experience Scale (ASEX) is a self-administered scale with five questions. It is designed to assess five major aspects of sexual dysfunction, drive, arousal, penile erection/vaginal lubrication, ability to reach orgasm, and satisfaction from orgasm. ${ }^{(24)}$ Items are measured on a 6-point scale (1 to 6), with higher scores reflecting impaired sexual function. This scale allows rapid detection of sexual dysfunction. Sexual dysfunction was defined as 1) a total ASEX score of $\geq 19,2$ ) any one item with a score of $\geq 5$, or 3 ) any three items with a score of $\geq$ 4. ${ }^{(24)}$ The reliability and validity of the ASEXChinese Version (ASEX-CV) have been established among patients with MDD by Wen, ${ }^{(25)}$ with a Cronbach alpha of 0.89 and a sensitivity and specificity for predicting sexual dysfunction of 0.74 and 0.84 , respectively. 
Three scales - the Hamilton Depression Rating Scale (HAMD), the Hospital Anxiety and Depression Scale (HADS), and the Depression and Somatic Symptoms Scale (DSSS) - were used to evaluate the severity of depression, anxiety, and somatic symptoms. ${ }^{(26-28)}$ The DSSS, a self-administered scale, includes 12 items for depression (depression subscale; DS) and 10 items for somatic symptoms (somatic subscale; SS), which includes five pain symptoms and five non-pain somatic symptoms. The validity and reliability of the DSSS have been reported in previous studies. ${ }^{(28-30)}$ The DS of the DSSS is composed of items regarding common depressive symptoms including fatigue, insomnia, poor appetite, loss of sexual desire, and others. Therefore, the somatic component comprises $33.3 \%$ (4/12) of the DS when these four symptoms are included in the somatic component. Within the 17-item HAMD, eight items are related to somatic symptoms, including initial, middle, and terminal insomnia, loss of appetite, loss of weight, general somatic symptoms, somatic anxiety symptoms, and loss of libido; therefore, the somatic component of the HAMD accounts for $34.6 \%$ of the total possible HAMD score when the eight items are included. The HADS comprises 7 items for anxiety (HADS-A) and 7 items for depression (HADS-D) and does not include any somatic symptom items. Of the 7 items of the HADS-D, five are markers for an anhedonic state. ${ }^{(31)}$

Both the HAMD and the DS include one item for sexual desire (14th item in the HAMD and the DS). When testing for a correlation between the ASEX-CV score and depression, anxiety, and somatic symptoms, the item for sexual desire may increase the correlation with the ASEX-CV score. To avoid this confounding effect, the total HAMD and DS scores in the study excluded the score of the item for sexual desire, and for further analysis, the total scores were calculated by adding the 16 remaining items of the HAMD $\left(\mathrm{HAMD}_{16}\right)$ and the 11 remaining items of the DS $\left(\mathrm{DS}_{11}\right)$. After subjects were enrolled in the study, they were asked to complete the selfadministered ASEX-CV, DSSS and HADS, and the HAMD was evaluated.

\section{Procedure}

The subjects accepted pharmacotherapy after enrollment. In the first four weeks, each patient was administered open-label venlafaxine (extended- release) at a fixed dosage of $75 \mathrm{mg}$ (one capsule) per day, which was used because it is effective in the treatment of depression and somatic symptoms. ${ }^{(32)}$ Zolpidem (10 mg per tablet) was prescribed as needed at night ${ }^{(33)}$ as insomnia is a common complaint in patients with MDD. Subjects were told that venlafaxine could be shifted to another antidepressant at any visit after the first if they were not able to tolerate it. Four weeks later, the subjects were invited to attend a follow-up, at which the ASEX-CV, the DSSS and the HADS were completed again and the HAMD was reevaluated by the same psychiatrist. The improvement percentage (IP) was calculated as (score at baseline - score post treatment)/score at baseline, of each scale or subscale.

\section{Statistical methods}

All statistical analyses were performed using SPSS 15.0 for Windows (SPSS Inc., Chicago, Illinois, U.S.A.). The independent $t$-test, paired $t$-test, chi-square test, and Pearson's correlation were used where appropriate. The independent $t$-test was used for comparison of continuous variables of the incomplete group and complete group at baseline; the chisquare test was used for comparison of categorical variables of the incomplete group and complete group at baseline. The paired $t$-test was used for the comparison of continuous variables at baseline v.s. at endpoint for the complete group. To identify the most powerful scales or subscales in terms of predicting the ASEX-CV score at baseline and the onemonth follow-up, multiple linear regression with forward selection was employed. This method has two advantages: 1) it can be used to identify the variables that most effectively predict the total ASEX-CV score and 2) it can prevent multicolinearity. In the regression models, the dependent variable was the total score of the ASEX-CV at baseline or follow-up. The independent variables were the scores of the three scales (the HAMD 16 , the $\mathrm{DS}_{11}$, the SS, the HADS-D, and the HADS-A scores) at the same time points and five patient variables, age, gender, years of education, marital status, and occupation. In all statistical analyses, a $p$ value $<0.05$ was considered statistically significant.

\section{RESULTS}

During the study period, 135 patients (34 men, 
101 women) were enrolled at baseline and 95 (70.4\%) subjects completed the one-month treatment course. Thirty $(22.2 \% ; 30 / 135)$ subjects did not complete the ASEX-CV scale at baseline and $20(21.1 \%$; 20/95) did not complete the scale at the one-month follow-up because these subjects did not engage in sexual activity in the month previous to enrollment. Overall, the $65(48.1 \%)$ subjects who did not complete the one-month pharmacotherapy or the ASEX$\mathrm{CV}$ were categorized into the incomplete group. The other $70(51.9 \%)$ subjects who completed the onemonth pharmacotherapy and the ASEX-CV at both baseline and follow-up were categorized into the complete group. Among the 70 subjects, 58 (82.9\%) were treated with venlafaxine, $8(11.4 \%)$ were shifted to paroxetine, and 4 were shifted to another antidepressant because of inability to tolerate the side effects of venlafaxine.

The scores of the three psychometric scales and the patient variables of the two groups are shown in Table 1. There were no significant differences in the HAMD, DS, SS, HADS-D, HADS-A, and patient variables between the incomplete and the complete group, except that subjects in the incomplete group were younger $(28.1 \pm 8.7 v s .32 .1 \pm 7.6 ; p<0.01)$ (Table 1). At endpoint, the scores of the HAMD 16
$\mathrm{DS}_{11}, \mathrm{SS}, \mathrm{HADS}-\mathrm{D}$ and HADS-A were significantly improved (Table 1). Moreover, the items for sexual desire in the HAMD $(1.1 \pm 0.8$ vs. $0.9 \pm 0.8 ; p=$ $0.02)$ and the DS $(1.7 \pm 1.0 v s .1 .0 \pm 1.1 ; p<0.01)$ were also significantly improved (not shown in tables). Table 2 shows the scores for each ASEX-CV item, which demonstrate that no significant improve-

Table 2. ASEX-CV Scores before and after 4 Weeks of Treatment with Venlafaxine in 70 Patients with Major Depressive Disorder

\begin{tabular}{lcc}
\hline & $\begin{array}{c}\text { Complete group } \\
\text { at baseline } \\
(\mathrm{n}=70)\end{array}$ & $\begin{array}{c}\text { Complete group } \\
\text { at endpoint } \\
(\mathrm{n}=70)\end{array}$ \\
\hline ASEX-CV 1 & $4.47 \pm 1.31$ & $4.30 \pm 1.39$ \\
ASEX-CV 2 & $3.47 \pm 1.07$ & $3.66 \pm 1.36$ \\
ASEX-CV 3 & $3.37 \pm 1.16$ & $3.40 \pm 1.29$ \\
ASEX-CV 4 & $3.59 \pm 1.23$ & $3.79 \pm 1.33$ \\
ASEX-CV 5 & $3.61 \pm 1.24$ & $3.54 \pm 1.46$ \\
Total score & $18.51 \pm 4.43$ & $18.69 \pm 5.91$ \\
Sexual dysfunction $(\%)$ & $71.43(\mathrm{n}=50)$ & $61.43(\mathrm{n}=43)$ \\
\hline
\end{tabular}

Abbreviation: ASEX-CV: Arizona Sexual Experience ScaleChinese Version

Table 1. Patient Variables and Psychometric Presentations of Depressive Patients before and after 4 Weeks of Treatment with Venlafaxine

\begin{tabular}{|c|c|c|c|}
\hline & $\begin{array}{l}\text { Incomplete group } \\
\qquad(\mathrm{n}=65)\end{array}$ & $\begin{array}{l}\text { Complete group at baseline } \\
\qquad(\mathrm{n}=70)\end{array}$ & $\begin{array}{l}\text { Complete group at endpoint } \\
\qquad(\mathrm{n}=70)\end{array}$ \\
\hline HAMD $_{16}$ & $22.0 \pm 4.7$ & $22.4 \pm 4.2$ & $11.6 \pm 6.8^{\dagger}$ \\
\hline $\mathrm{DS}_{11}$ & $23.9 \pm 4.8$ & $23.7 \pm 4.9$ & $12.5 \pm 7.1^{\dagger}$ \\
\hline SS & $14.9 \pm 7.1$ & $17.0 \pm 6.0$ & $9.5 \pm 6.1^{\dagger}$ \\
\hline HADS-D & $14.2 \pm 3.7$ & $13.9 \pm 3.3$ & $10.0 \pm 4.4^{\dagger}$ \\
\hline HADS-A & $15.5 \pm 3.4$ & $15.0 \pm 3.1$ & $9.8 \pm 4.3^{\dagger}$ \\
\hline Age (years) & $28.1 \pm 8.7^{*}$ & $32.1 \pm 7.6$ & - \\
\hline Years of education & $13.0 \pm 2.4$ & $13.1 \pm 2.4$ & - \\
\hline Gender (female; \%) & 78.5 & 71.4 & - \\
\hline Paid employment (Yes; \%) & 49.2 & 60.0 & - \\
\hline Married (Yes; \%) & 38.5 & 52.9 & - \\
\hline
\end{tabular}

Abbreviations: $\mathrm{HAMD}_{16}$ : the Hamilton Depression Rating Scale, excluding the item for sexual desire; $\mathrm{DS}_{11}$ : the depression subscale of the Depression and Somatic Symptoms Scale (DSSS), excluding the item for sexual desire; SS: the somatic subscale of the DSSS; HADSD: the depression subscale of the Hospital Anxiety and Depression Scale (HADS); HADS-A: the anxiety subscale of the HADS; *: $p<$ $0.05 ; \uparrow: p<0.01$. 
ment was observed in any of the ASEX-CV items at endpoint.

The IPs of the following scales at endpoint were as follows: total ASEX-CV score, $-1.6 \pm 24.7$; HAMD $_{16}, 48.5 \pm 27.3 ; \mathrm{DS}_{11}, 47.9 \pm 25.2 ; \mathrm{SS}, 44.1$ \pm 31.3; HADS-D, $26.0 \pm 31.6$; and HADS-A, 34.7 \pm 25 (not shown in tables).

Correlation of each ASEX-CV item with the three psychometric scales at baseline and onemonth follow up

Table 3 shows the correlation of each ASEX-CV item with the three psychometric scales at baseline. The HADS-D was significantly correlated with the $2^{\text {nd }}, 3^{\text {rd }}$, and $4^{\text {th }}$ items and the total ASEX-CV score. The $\mathrm{DS}_{11}$ was significantly correlated with the $3^{\text {rd }}$ and $4^{\text {th }}$ items. The HAMD 16 , the SS, and the HADS-
A were not significantly correlated with any of the ASEX-CV items nor with the total score.

Table 4 presents the correlation of each ASEX$\mathrm{CV}$ item with the three psychometric scales after the one-month treatment. The HADS-D and the $\mathrm{DS}_{11}$ were significantly correlated with each item and the total score of the ASEX-CV, with the exception item 5 on the $\mathrm{DS}_{11}$. The HAMD 16 and the HADS-A were significantly correlated with the total score and some items of the ASEX-CV. The SS was not significantly correlated with any item of the ASEX-CV.

At the two points, the HADS-D tended to be correlated with the most ASEX-CV items, followed by the $\mathrm{DS}_{11}$ and the HAMD 16 . The SS was not correlated with any of the ASEX-CV items. Among the five items, item 5 of the ASEX-CV was not correlated with any of the three psychometric scales except

Table 3. Pearson's Correlation Coefficients of the Different ASEX-CV Items and the Three Psychometric Scales Evaluated at Baseline

\begin{tabular}{lcccccc}
\hline & ASEX-CV 1 & ASEX-CV 2 & ASEX-CV 3 & ASEX-CV 4 & ASEX-CV 5 & ASEX-CV total \\
\hline HAMD $_{16}$ & 0.10 & 0.11 & 0.18 & 0.20 & -0.20 & 0.16 \\
DS $_{11}$ & 0.10 & 0.17 & $0.24^{*}$ & $0.25^{*}$ & -0.01 & 0.20 \\
SS & 0.12 & 0.15 & 0.13 & 0.20 & 0.11 & 0.19 \\
HADS-D & 0.10 & $0.30^{*}$ & $0.29^{*}$ & $0.24^{*}$ & 0.10 & $0.27^{*}$ \\
HADS-A & -0.01 & 0.03 & 0.06 & 0.01 & -0.10 & -0.01 \\
\hline
\end{tabular}

Abbreviations: ASEX-CV: the Arizona Sexual Experience Scale-Chinese Version; HAMD 16 : the Hamilton Depression Rating Scale, excluding the item for sexual desire; $\mathrm{DS}_{11}$ : the depression subscale of the Depression and Somatic Symptoms Scale (DSSS), excluding the item for sexual desire; SS: the somatic subscale of the DSSS; HADS-D: the depression subscale of the Hospital Anxiety and Depression Scale (HADS); HADS-A: the anxiety subscale of the HADS; *: $p<0.05$.

Table 4. Pearson's Correlation Coefficients of the Different ASEX-CV Items and the Three Psychometric Scales Evaluated after 4 Weeks of Treatment with Venlafaxine

\begin{tabular}{lcccccc}
\hline & ASEX-CV 1 & ASEX-CV 2 & ASEX-CV 3 & ASEX-CV 4 & ASEX-CV 5 & ASEX-CV total \\
\hline HAMD $_{16}$ & $0.25^{*}$ & $0.27^{*}$ & 0.22 & $0.29^{*}$ & 0.10 & $0.26^{*}$ \\
DS $_{11}$ & $0.28^{*}$ & $0.28^{*}$ & $0.28^{*}$ & $0.33^{*}$ & 0.12 & $0.30^{*}$ \\
SS & 0.21 & 0.23 & 0.22 & 0.21 & 0.08 & 0.22 \\
HADS-D & $0.50^{\dagger}$ & $0.45^{\dagger}$ & $0.40^{\dagger}$ & $0.41^{\dagger}$ & $0.26^{\dagger}$ & $0.46^{\dagger}$ \\
HADS-A & $0.33^{\dagger}$ & 0.23 & 0.20 & $0.30^{*}$ & 0.16 & $0.28^{*}$ \\
\hline
\end{tabular}

Abbreviations: ASEX-CV: the Arizona Sexual Experience Scale-Chinese Version; HAMD ${ }_{16}$ : the Hamilton Depression Rating Scale, excluding the item for sexual desire; $\mathrm{DS}_{11}$ : the depression subscale of the Depression and Somatic Symptoms Scale (DSSS), excluding the item for sexual desire; SS: the somatic subscale of the DSSS; HADS-D: the depression subscale of the Hospital Anxiety and Depression Scale (HADS); HADS-A: the anxiety subscale of the HADS; $*: p<0.05 ; \dagger: p<0.01$. 
for the HADS-D at endpoint.

\section{Independent factors associated with the total score of the ASEX}

The HADS-D was the only factor found to independently predict the total ASEX-CV score at baseline $($ Beta $=0.27 ; p=0.02)$ and at endpoint $($ Beta $=$ $0.46 ; p<0.001$ ) (not shown in tables). The final $\mathrm{R}$ square for the regression model at baseline was 0.13 , which was partially explained by the HADS-D (R square change $=0.08$ ). This means that the HADS-D score explained $8 \%$ of the variance of the total ASEX-CV score at baseline. The final $\mathrm{R}$ square for the regression model at endpoint was 0.18 , which was fully explained by the HADS-D (not shown in tables). This means that the HADS-D score explained $18 \%$ of the variance of the total ASEX-CV score at endpoint. Both at baseline and endpoint, the HADS-D was the only significant predictor of the total ASEX-CV score and subjects with higher HADS-D scores were more likely to have higher ASEX-CV scores. That is, the subjects with severe depression had worse sexual function. The HAMD, DS, SS, HADS-A, and other demographic variables were not entered into the three regression models.

\section{DISCUSSION}

Among the three psychometric scales, the HADS-D was the only subscale entered into the regression models to independently predict the total score of the ASEX-CV after controlling for patient variables at baseline and posttreatment. The HADS$\mathrm{D}$ was correlated with more individual ASEX-CV items than the HAMD 16 and the other subscales at the two points. The clinical implications arising from our results were as follows: 1) sexual dysfunction was more correlated with depression than with anxiety and somatic symptoms; 2) the ASEX-CV was not correlated with the SS at either of the two points.

The HADS-D was more correlated with ASEX$\mathrm{CV}$ score than the HAMD ${ }_{16}$, and the $\mathrm{DS}_{11}$. This might result from the fact that the HAMD 16 and the $\mathrm{DS}_{11}$ also include several somatic symptoms, such as fatigue, insomnia, decreased appetite or weight, and other somatic anxiety symptoms. However, the HADS-D, which is especially focused on the anhedonic state, ${ }^{(31)}$ does not include any somatic symptoms. In fact, previous studies have reported that sex- ual dysfunction among patients with depression is strongly correlated with an anhedonic state. ${ }^{(12,34)}$ As described above, sexual dysfunction may be more related to the anhedonic component of depression than to the somatic component of depression. Our results implied that pharmacotherapy for MDD should be more focused on depression, especially the anhedonic state, when improvement of sexual dysfunction is an important issue for patients with MDD.

Several points are worthy of note, (1) The IP of the total score of the ASEX-CV was negative $(-1.6$ \pm 24.7). However, the IPs of the three psychometric scales were positive $\left(\mathrm{HAMD}_{16}, 48.5 \pm 27.3 \mathrm{DS}_{11}\right.$, $47.9 \pm 25.2$; SS, $44.1 \pm 31.3$; HADS-D, $26.0 \pm$ 31.6; and HADS-A, $34.7 \pm 25)$. Previous studies have reported that improvement of sexual dysfunction is related to improvement of depression among patients with MDD. ${ }^{(35)}$ One previous study suggested that genital symptoms (level of sexual interest or ease of sexual arousal) showed a later response to antidepressant treatment than depressed mood and general somatic symptoms. ${ }^{(21)}$ It is also possible that the negative IP of the total ASEX-CV score may be a result of sexual function being affected by the side effects of antidepressant treatment ${ }^{(36)}$ during the 4 weeks of pharmacotherapy. (2) At baseline and endpoint, the $5^{\text {th }}$ item of the ASEX-CV (satisfaction from orgasm) was not significantly correlated with depression, anxiety, and somatic symptoms, except for the HADS-D at the 4-week point. Some studies have reported that satisfaction from orgasm is related to the relationship with the partner, perception of the partner's sexual dysfunction ${ }^{(20)}$ and frequency of sexual intercourse. ${ }^{(37)}$ (3) Although the changes in the five items and the total score of the ASEX-CV were not significant at endpoint, the scores of the $2^{\text {nd }}, 3^{\text {rd }}$, and $4^{\text {th }}$ items were increased by a small degree at endpoint, which implied that the three items may be more apt to be affected by antidepressant side effects. In fact, a recent meta-analysis illustrated that antidepressants affect specific phases (including desire, arousal and orgasm) of sexual function, ${ }^{(38)}$ which is compatible with our results.

There were several methodological issues or limitations in this study. (1) Our study enrolled MDD outpatients in a medical center using several exclusion criteria. Some subjects did not complete the ASEX-CV because they did not engage in sexual 
activity in the month previous to enrollment. In the first month, venlafaxine was prescribed at a fixed dosage, however, 12 subjects were shifted to other antidepressants in the complete group. Bias might therefore have been introduced during this enrollment and treatment process. (2) The study was a single-site study with a limited number of participants. (3) The treatment duration was selected as four weeks, because this time point has been reported as being one of the important milestones after which treatment response can be predicted or observed. ${ }^{(39,40)}$ Although an early treatment response is a predictive factor of late prognosis, ${ }^{(41)}$ the short treatment duration, which was not sufficient to correct sexual dysfunction due to the symptoms of depression, might be one of the reasons for a lack of improvement in the ASEX-CV score. Moreover, the adverse effects of treatment were also a possible reason for the lack of improvement in the ASEX-CV score. (4) Our subjects were patients with MDD. It is unknown whether the relationships between sexual dysfunction, depression, anxiety, and somatic symptoms differ in other populations. Moreover, different antidepressants might also affect the IPs of different dimensions post-pharmacotherapy. (5) In our study, $71.4 \%$ of the participants were women, so there may be some gender bias in the results. (6) Although it has been reported that venlafaxine has a lower rate of sexual dysfunction than serotonin-specific reuptake inhibitors, ${ }^{(6)}$ it still had the potential side effect of sexual dysfunction. Therefore, using venlafaxine in this study might have caused bias.

In conclusion, the total ASEX-CV score was most correlated with the depressive dimension (anhedonic state) of MDD. The ASEX-CV score was not correlated with somatic symptoms. Further studies to explore the relationships between sexual dysfunction, depression, anxiety, and somatic symptoms in other populations may be indicated.

\section{REFERENCES}

1. Kennedy SH, Rizvi S. Sexual dysfunction, depression, and the impact of antidepressants. J Clin Psychopharmacol 2009;29:157-64.

2. Smith JF, Breyer BN, Eisenberg ML, Sharlip ID, Shindel AW. Sexual function and depressive symptoms among male North American medical students. J Sex Med 2010;7:3909-17.
3. Kennedy SH, Dickens SE, Eisfeld BS, Bagby RM. Sexual dysfunction before antidepressant therapy in major depression. J Affect Disord 1999;56:201-8.

4. Tuinman MA, Hoekstra HJ, Vidrine DJ, Gritz ER, Sleijfer DT, Fleer J, Hoekstra-Weebers JE. Sexual function, depressive symptoms and marital status in nonseminoma testicular cancer patients: A longitudinal study. Psychooncology 2010;19:238-47.

5. Chen KC, Yeh TL, Lee IH, Chen PS, Huang HC, Yang YK, Shen WW, Lu RB. Age, gender, depression, and sexual dysfunction in Taiwan. J Sex Med 2009;6:3056-62.

6. Kennedy SH, Eisfeld BS, Dickens SE, Bacchiochi JR, Bagby RM. Antidepressant-induced sexual dysfunction during treatment with moclobemide, paroxetine, sertraline, and venlafaxine. J Clin Psychiatry 2000;61:276-81.

7. Coleman CC, Cunningham LA, Foster VJ, Batey SR, Donahue RM, Houser TL, Ascher JA. Sexual dysfunction associated with the treatment of depression: A placebocontrolled comparison of bupropion sustained release and sertraline treatment. Ann Clin Psychiatry 1999;11:205-15.

8. Clayton A, Kornstein S, Prakash A, Mallinckrodt C, Wohlreich M. Changes in sexual functioning associated with duloxetine, escitalopram, and placebo in the treatment of patients with major depressive disorder. J Sex Med 2007;4:917-29.

9. Montejo AL, Perahia DG, Spann ME, Wang F, Walker DJ, Yang CR, Detke MJ. Sexual function during longterm duloxetine treatment in patients with recurrent major depressive disorder. J Sex Med 2011;8:773-82.

10. Schnatz PF, Whitehurst SK, O'Sullivan DM. Sexual dysfunction, depression, and anxiety among patients of an inner-city menopause clinic. J Womens Health 2010;19: 1843-9.

11. Laurent SM, Simons AD. Sexual dysfunction in depression and anxiety. Conceptualizing sexual dysfunction as part of an internalizing dimension. Clin Psychol Rev 2009;29:573-85.

12. Johnson SD, Phelps DL, Cottler LB. The association of sexual dysfunction and substance use among a community epidemiological sample. Arch Sex Behav 2004;33:5563.

13. Balon R. Mood, anxiety and physical illness. Body and mind, or mind and body? Depress Anxiety 2006;23:37787.

14. Beck JG, Bozman AW. Gender differences in sexual desire. The effects of anger and anxiety. Arch Sex Behav 1995;24:595-612.

15. Kapfhammer HP. Somatic symptoms in depression. Dialogues Clin Neurosci 2006;8:227-39.

16. Tajar A, O'Neill TW, Lee DM, O'Connor DB, Corona G, Finn JD, Bartfai G, Boonen S, Casanueva FF, Forti G, Giwercman A, Han TS, Huhtaniemi IT, Kula K, Lean ME, Pendleton N, Punab M, Purandare N, Silman AJ, Vanderschueren D, Wu FC, McBeth J. The effect of musculoskeletal pain on sexual function in middle-aged and 
elderly European men: results from the European male ageing study. J Rheumatol 2011;38:370-7.

17. Janssens KA, Rosmalen JG, Ormel J, van Oort FV, Oldehinkel AJ. Anxiety and depression are risk factors rather than consequences of functional somatic symptoms in a general population of adolescents: the TRAILS study. J Child Psychol Psychiatry 2010;51:304-12.

18. Kalichman L. Association between fibromyalgia and sexual dysfunction in women. Clin Rheumatol 2009;28:3659.

19. ter Kuile MM, Weijenborg PT, Spinhoven P. Sexual functioning in women with chronic pelvic pain: the role of anxiety and depression. J Sex Med 2010;7:1901-10.

20. Jiann BP, Su CC, Yu CC, Wu TT, Huang JK. Risk factors for individual domains of female sexual function. J Sex Med 2009;6:3364-75.

21. Hirschfeld RM, Mallinckrodt C, Lee TC, Detke MJ. Time course of depression-symptom improvement during treatment with duloxetine. Depress Anxiety 2005;21:170-7.

22. American Psychiatric Association. Diagnostic and Statistical Manual of Mental Disorders. 4th ed. Washington, DC: American Psychiatric Publishing, 2000.

23. First MB, Gibbon M, Williams JBW. Structured clinical interview for DSM-IV-TR Axis I disorders, research version, patient edition (SCID-I/P). New York: Biometrics Research, New York State Psychiatric Institute, 2002.

24. McGahuey C, Gelenberg AJ, Laukes CA, Moreno FA, Delgado PL, McKnight KM, Manber R. The Arizona Sexual Experience Scale (ASEX): reliability and validity. J Sex Marital Ther 2000;26:25-40.

25. Wen JK, Hung CF, Chen SW, Jing JH, Chu YJ. Validity and reliability of Arizona Sexual Experiences ScaleChinese Version (ASEX-CV) in the clinical study of outpatients with depressive disorder and sexual dysfunction. Proceedings of the Annual Meeting of the Taiwanese Society of Psychiatry. Tainan: Taiwanese Society of Psychiatry, 2006:119-20.

26. Hamilton M. Development of a rating scale for primary depressive illness. Br J Soc Clin Psychol 1967;6:278-96.

27. Zigmond AS, Snaith RP. The Hospital Anxiety and Depression Scale. Acta Psychiatr Scand 1983;67:361-70.

28. Hung CI, Weng LJ, Su YJ, Liu CY. Depression and Somatic Symptoms Scale: a new scale with both depression and somatic symptoms emphasized. Psychiatry Clin Neurosci 2006;60:700-8.

29. Hung CI, Wang SJ, Liu CY. Validation of the Depression and Somatic Symptoms Scale by comparison with the Short Form 36 scale among psychiatric outpatients with major depressive disorder. Depress Anxiety 2009;26:583-
91.

30. Hung CI, Liu CY, Wang SJ, Juang YY, Yang CH. Somatic symptoms. An important index in predicting the outcome of depression at six-month and two-year follow-up points among outpatients with major depressive disorder. J Affect Disord 2010;125:134-40.

31. Kendel F, Wirtz M, Dunkel A, Lehmkuhl E, Hetzer R, Regitz-Zagrosek V. Screening for depression: Rasch analysis of the dimensional structure of the PHQ-9 and the HADS-D. J Affect Disord 2010;122:241-6.

32. Stahl SM, Grady MM, Moret C, Briley M. SNRIs: their pharmacology, clinical efficacy, and tolerability in comparison with other classes of antidepressants. CNS Spectr 2005;10:732-47.

33. Swainston Harrison T, Keating GM. Zolpidem: A review of its use in the management of insomnia. CNS Drugs 2005; 19:65-89.

34. Hirschfeld RM. Care of the sexually active depressed patient. J Clin Psychiatry 1999;60 Suppl 17:32-5.

35. Baldwin D, Moreno RA, Briley M. Resolution of sexual dysfunction during acute treatment of major depression with milnacipran. Hum Psychopharmacol 2008;23:52732.

36. Kennedy SH, McCann SM, Masellis M, McIntyre RS, Raskin J, McKay G, Baker GB. Combining bupropion sr with venlafaxine, paroxetine, or fluoxetine: A preliminary report on pharmacokinetic, therapeutic, and sexual dysfunction effects. J Clin Psychiatry 2002;63:181-6.

37. Nicolosi A, Moreira ED, Jr., Villa M, Glasser DB. A population study of the association between sexual function, sexual satisfaction and depressive symptoms in men. $\mathrm{J}$ Affect Disord 2004;82:235-43.

38. Serretti A, Chiesa A. Treatment-emergent sexual dysfunction related to antidepressants: a meta-analysis. J Clin Psychopharmacol 2009;29:259-66.

39. Trivedi MH, Morris DW, Grannemann BD, Mahadi S. Symptom clusters as predictors of late response to antidepressant treatment. J Clin Psychiatry 2005;66:1064-70.

40. Quitkin FM, McGrath PJ, Stewart JW, Ocepek-Welikson K, Taylor BP, Nunes E, Deliyannides D, Agosti V, Donovan SJ, Petkova E, Klein DF. Chronological milestones to guide drug change. When should clinicians switch antidepressants? Arch Gen Psychiatry 1996;53: 785-92.

41. Mulder RT, Joyce PR, Frampton CM, Luty SE, Sullivan PF. Six months of treatment for depression: Outcome and predictors of the course of illness. Am J Psychiatry 2006;163:95-100. 


\title{
憂鬱症病患之性功能障礙與憂缽、焦虑及身體症狀之間的關係
}

\author{
林俏沉 莊永毓 文榮光 ${ }^{1}$ 劉嘉逸 洪錦益
}

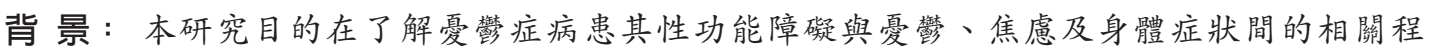
度, 並了解何者對於性功能障礙最有預測性。

方 法: 本研究納入 135 個門診憂鐢症個案, 以 venlafaxine $75 \mathrm{mg}$ 治療一個月。使用中文版 亞利桑那性經驗量表 (Arizona Sexual Experience Scale-Chinese Version)、憂䙪及身體 症狀量表 (Depression and Somatic Symptoms Scale)、漢氏憂礬量表 (Hamilton Depression Rating Scale) 及醫院焦虑憂礬量表 (Hospital Anxiety and Depression Scale) 來評估治療前與治療一個月後各層面的改善比率。統計方法使用多元線性迴歸來找 出最能預測性功能障礙的因子。

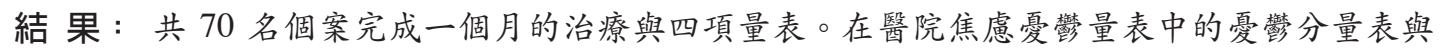
中文版亞利桑那性經驗量表的相關最強, 同時該分量表也是最能獨立預測治療前後 中文版亞利桑那性經驗量表之變項。然而, 憂礬及身體症狀量表的身體分量表與中

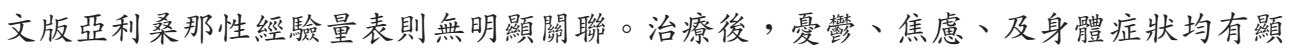
著改善（改善比率 48.5\% 到 26.0\%), 但中文版亞利桑那性經驗量表卻沒有改善（改 善比率 $-1.6 \%)$ 。

結 論: 憂礬症病人其性功能障礙與憂礬症狀最有關, 但與身體症狀無關。未來的研究需更 進一步來了解性功能障礙與憂䙪、焦虑及身體症狀間的關聯性。

(長庚醫誌 2012;35:323-31)

關鍵詞：性功能障礙，憂柁，焦虑，身體症狀

長庚醫療財團法人林口長庚醫院 精神科 ; 長庚大學 醫學院 ; 1高雄仁愛之家附設慈惠醫院

受文日期：民國100年6月21日；接受刊載：民國100年12月28日

通訊作者: 洪錦益醫師, 長庚醫療財團法人林口長庚醫院 精神科。桃園縣333龜山鄉復興街5號。Tel: (03)3281200轉2439;

Fax: (03)3280267; E-mail: a36250@cgmh.org.tw 